\title{
Supplementary Material
}

There are no supplementary material for this manuscript. The data used in this study is in the following website:

www.dGBes.com 